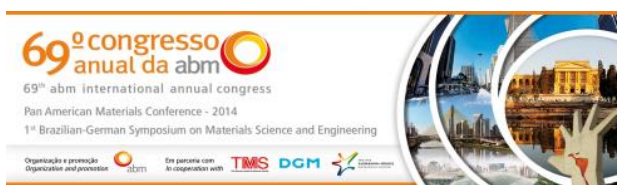

Tema: Forjamento

\title{
ESTUDO DAS CARACTERISTICAS DO PROCESSO DE SINTERFORJAMENTO DO AÇO AISI 4140: ANÁLISE DAS PROPRIEDADES MECÂNICAS DE BILLETS OBTIDOS POR METALURGIA DO PÓ*
}

\section{Resumo}

\author{
Luana De Lucca de Costa \\ André Carvalho Tavaes ${ }^{2}$ \\ Fábio Junkes Corrêa ${ }^{3}$ \\ Diego Pacheco Wermut 4 \\ Vinicius Martins ${ }^{5}$ \\ Lirio Schaeffer ${ }^{6}$
}

Este trabalho é um estudo sobre os aspectos tecnológico de sinter forjamento, onde são realizadas alterações nos parâmetros temperatura e deformação. Experimentos foram realizados para o estudo das variações microestruturais, e propriedades, tais como, densificação e dureza, e, ainda, quais as variações na força empregada para obtenção das deformações estabelecidas. A relação entre a tensão de atrito na interface e outras variáveis do processo é discutida e uma análise feita para o cálculo da distribuição da pressão e carga a partir das equações de equilíbrio. Os resultados são discutidos e os parâmetros de processamento envolvidos durante o processo de sínter forjamento são analisados.

Palavras-chave: Forjamento de pós-metálicos; Sinterforjamento; Aço AISI 4140 e metalurgia do pó.

\section{STUDY OF THE CHARACTERISTICS OF THE SINTERFORGING PROCESS STEEL AISI 4140: ANALYSIS OF THE MECHANICAL PROPERTIES OF BILLETS OBTAINED BY POWDER METALLURGY}

\section{Abstract}

This work is a study on the technological aspects of sinter forging, where changes in temperature and deformation parameters are performed. Experiments were carried out to study the microstructural variations, and properties such as hardness and densification, and also variations in which the force used to obtain the deformation established. The relationship between the shear stress at the interface and other process variables is discussed and an analysis to calculate the distribution of pressure load from the equations of equilibrium. The results are discussed and processing parameters involved during the sinter forging process are analyzed.

Keywords: Forging metal powders; sinterforging; AISI 4140 Steel and powder metallurgy.

1 Engenheira Mecânica, Mestranda do PPGEM, LdTM, UFRGS, Porto Alegre, RS, Brasil; luana.lucca@ufrgs.br.

2 Tecnólogo em Fabricação Mecânica, Mestre em Eng. pelo Programa de Pós-Graduação em Engenharia de Minas, Metalúrgica e Materiais (PPGEM), Laboratório de Transformação Mecânica (LdTM), Universidade Federal do Rio Grande do Sul (UFRGS), Porto Alegre, RS, Brasil; andre.tavares@ufrgs.br.

3 Engenheiro Mecânico, Mestre em Eng. pelo PPGEM, LdTM, UFRGS, Porto Alegre, RS, Brasil; fabio.correa@ufrgs.br.

4 Tecnólogo em Fabricação Mecânica, Mestre em Eng. pelo PPGEM, LdTM, Universidade Federal do Rio Grande do Sul (UFRGS), Porto Alegre, RS, Brasil; diego.wermut@ufrgs.br.

5 Mestre Tecnólogo em Fabricação Mecânica, Professor, Instituto Federal Sul Rio-grandense IFSul, Campus Sapucaia do Sul. Doutorando do PPGEM, LdTM, UFRGS, Porto Alegre, RS, Brasil; viniciushiper@yahoo.com.

6 Prof. Dr.-Ing, Coordenador do Laboratório de Transformação Mecânica (LdTM), Universidade Federal do Rio Grande do Sul (UFRGS), Porto Alegre, RS, Brasil; schaefer@ufrgs.br.

\footnotetext{
* Contribuição técnica ao 69ำ Congresso Anual da ABM - Internacional e ao 14ํㅡㄹ ENEMET - Encontro Nacional de Estudantes de Engenharia Metalúrgica, de Materiais e de Minas, 21 a 25 de julho de 2014, São Paulo, SP, Brasil.
} 


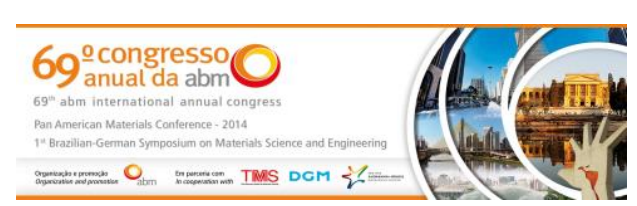

\section{INTRODUÇÃO}

A metalurgia do pó é um processo de fabricação versátil e eficiente para a produção de componentes de aço com combinações de vários elementos de liga. Esses elementos de liga melhoram significativamente a capacidade de endurecimento por deslocamento das curvas de transformação para tempos de transformação mais longo.

Parte-se de uma mistura de pós metálicos, que facilita a possibilidade de criar ligas. 0 pó pode ser moldado via compactação, extrusão, sinterização, ou sinterforjamento, em que o pó sofre uma pré-sinterização para eliminar o lubrificante, depois o material é aquecido e forjado. Na moldagem por injeção o pó de metal pode ser combinado com polímeros aditivos.

Pré-formas obtidas por sinterização de pós metálicos compactados estão sendo utilizadas nos processos de forjamento e representam um método econômico para produção de produtos de alta densificação e melhoria nas propriedades mecânicas. Esta tecnologia permite que o pó de metal compactado e sinterizado seja utilizado como pré-forma para formar peças forjadas com dimensionamento final superiores as obtidas a partir de pré-formas oriundas de outros processos de fabricação, além, de melhores propriedades mecânicas e metalúrgicas devido a homogeneidade da distribuição dos grãos. O ciclo produtivo de peças sinterforjadas está representado esquematicamente na Figura $1[1,2]$.

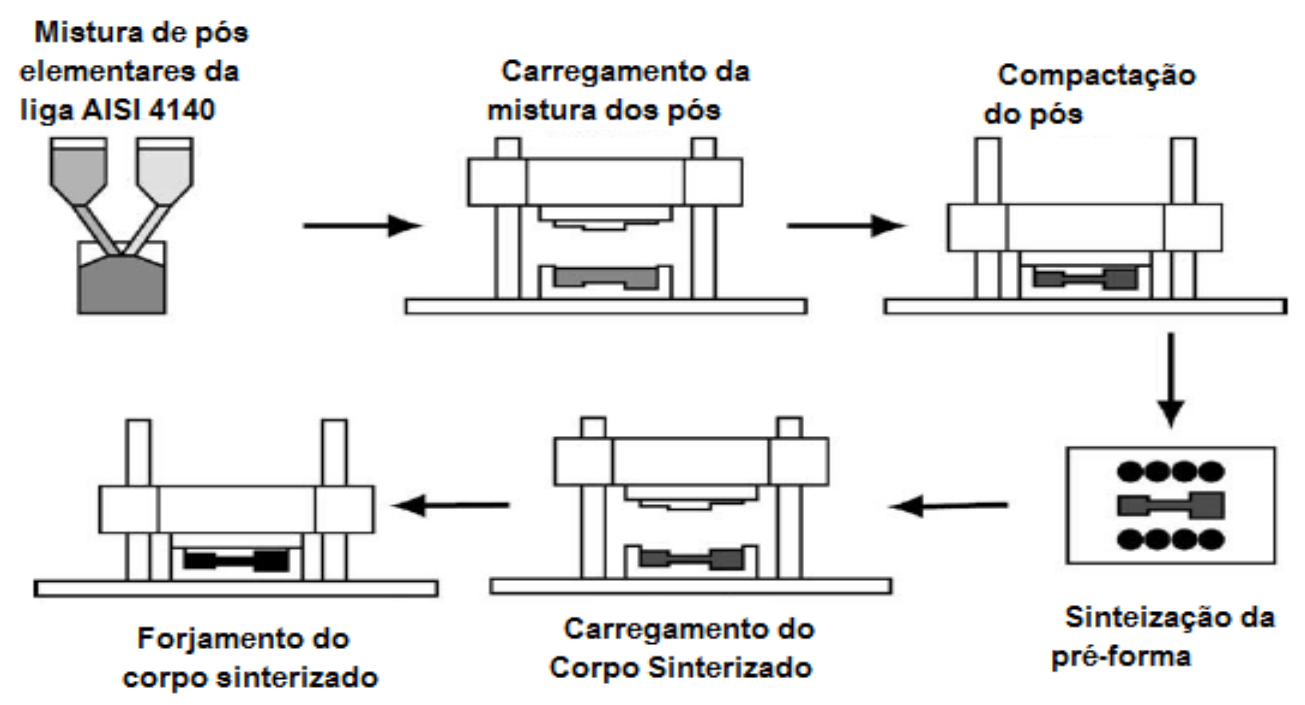

Figura 1. Ciclo esquemático do Sinter forjamento [1].

O padrão de deformação durante o forjamento de copos sintetizados é diferente do convencional, pois, as características do material poroso passando por deformação são de fundamental importância, pois, a eliminação dos poros, iniciada no inicio da deformação plástica, ocasiona uma mudança de densidade, conforme demonstra a Figura 2. Outra característica importante é que os componentes obtidos por sinterização de pós têm baixa tensão hidrostática diferente dos billets e pré-formas obtidos por outros processos de fabricação $[3,4]$.

\footnotetext{
* Contribuição técnica ao $69^{\circ}$ Congresso Anual da ABM - Internacional e ao 14ํㅡㄹ ENEMET - Encontro Nacional de Estudantes de Engenharia Metalúrgica, de Materiais e de Minas, 21 a 25 de julho de 2014, São Paulo, SP, Brasil.
} 


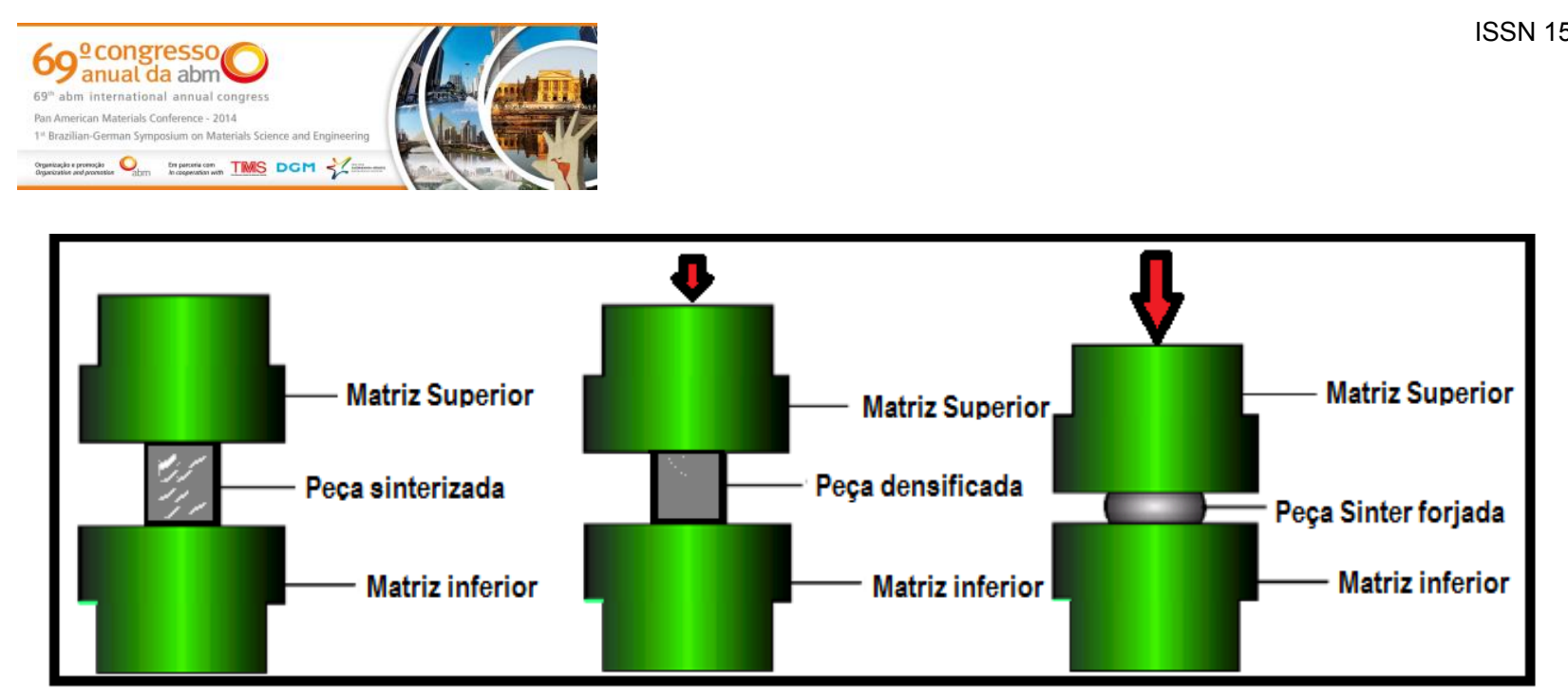

Figura 2. Etapas simplificadas do Sinterforjamento em Matriz aberta.

Os principais fatores determinantes no processo de sínter forjamento são a densidade da pré-forma, as condições de lubrificação na interface matriz/peça, o fluxo tensão no corpo sinterizado e os relacionados ao equipamento, tais como, taxa de deformação, velocidade de deformação e carga aplicada [5]. A predeterminação da ocorrência de defeitos nos produtos obtidos por este processo requer compreensão do mecanismo de deformação e distribuição de pressão na interface do material sinterizado, juntamente com as diferenças na distribuição de porosidades e tensão residuais, a fim de garantir que a peça obtenha propriedades superiores depois de forjada $[5,6]$.

Diversos trabalhos foram relatados recentemente e abrangem diversos aspectos tecnológicos do processamento industrial de produtos sinterizados, porém, ainda estão em fase de tentativas para prever as propriedades mecânicas dos materiais sinterizados, não existindo solução para previsão sistemática dos efeitos dinâmicos durante o sinterforjamento devido a alta velocidade no processo $[2,4]$.

Nos últimos anos o interesse na elevada velocidade de trabalho tem crescido consideravelmente, devido à necessidade de produção para satisfazer a demanda do mercado, com isso, a introdução de técnicas de conformação novas e rápidas estão tornando-se imprescindíveis e tornando a investigação do efeito das forças de inércia, durante a sinterforjamento, essenciais para possibilitar alta velocidade ao processo $[5,7]$.

O objetivo de trabalho é estudar os efeitos dinâmicos, microestruturais e a dureza a partir de diferentes padrões de reduções no sinterforjamento em alta velocidade. Corpos de prova obtidos por metalurgia do pó na composição do aço AISI 4140 foram preparados e forjados à temperatura ambiente e $1.200^{\circ} \mathrm{C}$. Aferições foram realizadas para a verificação da deformação por embarrigamento dos corpos de prova, também, análises microscópicas das variações na microestrutura longitudinal e transversal e verificação da densificação durante o processo.

A relação entre a tensão de atrito na interface e outras variáveis são analisadas juntamente com o cálculo da distribuição da pressão. As soluções das equações de equilíbrio levam em consideração o embarrigamento para a simetria axial ao plano de deformação do sinter-forjamento. Os resultados são discutidos de forma crítica para ilustrar a interação dos parâmetros de processamento durante o processo e são graficamente apresentados. Espera-se que o presente trabalho tenha relevada importância prática na concepção de equipamentos e ferramentas necessários para dispor de alta velocidade o processo de sínter forjamento.

\footnotetext{
* Contribuição técnica ao $69^{\circ}$ Congresso Anual da ABM - Internacional e ao 14ํㅡㄹ ENEMET - Encontro Nacional de Estudantes de Engenharia Metalúrgica, de Materiais e de Minas, 21 a 25 de julho de 2014, São Paulo, SP, Brasil.
} 


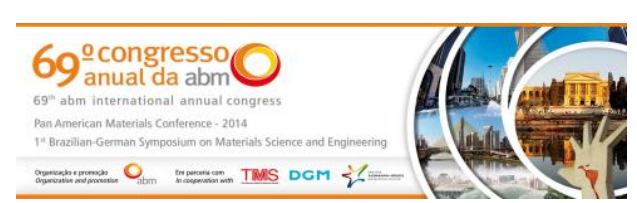

\section{MATERIAIS E MÉTODOS}

No presente trabalho foram avaliadas amostras de aço AISI 4140 provenientes do processo de laminação e por metalurgia do pó através mistura de pós elementares, com as dimensões de $13 \mathrm{~mm}$ de diâmetro e altura de aproximadamente $20 \mathrm{~mm}$, ambas foram submetidas a ensaios de compressão análogos ao processo de forjamento em matriz aberta.

Para a compactação dos pós elementares do aço AISI4140 foi realizada a mistura de elementos nas porcentagens apresentadas na Tabela 1. Utilizando uma balança de precisão mediu-se os percentuais para a mistura, resultando $300 \mathrm{~g}$ em massa para efetuar a mistura, sendo utilizado o misturador rotativo de duplo cone por trinta minutos a 22 rpm. Adicionou-se 1,5\% de parafina à massa total da mistura para obter maior resistência a verde dos corpos de prova compactados. Essa mistura foi suavemente aquecida até a fusão da parafina e homogeneização da massa.

Tabela 1. Composição química do AISI 4140 a partir de pós elementares

\begin{tabular}{|c|c|c|c|c|c|}
\hline $\mathrm{C}$ & $\mathrm{Si}$ & $\mathrm{Mn}$ & Mo & $\mathrm{Cr}$ & $\mathrm{Fe}$ \\
\hline $0,40 \%$ & $0,25 \%$ & $0,88 \%$ & $0,2 \%$ & $0,95 \%$ & $97,325 \%$ \\
\hline $0,12 \mathrm{~g}$ & $0,75 \mathrm{~g}$ & $2,85 \mathrm{~g}$ & $0,6 \mathrm{~g}$ & $2,85 \mathrm{~g}$ & $291,98 \mathrm{~g}$ \\
\hline
\end{tabular}

A mistura foi pesada e fracionada em dez partes iguais que posteriormente foram compactadas em uma matriz uniaxial cilíndrica com diâmetro de 13,0mm, sob pressões de compactação aplicadas variando entre 100 e $1000 \mathrm{MPa}$. As amostras foram compactadas e suas massas medidas para calcular as densidades a verde 0 que possibilitou a construção da curva de compressibilidade dos corpos de prova para seleção das pressões de compactação ideais às condições do experimento. As pressões de compactação apresentaram resultados de densificação em função da pressão exercida.

A sinterização ocorreu na temperatura de $1.150^{\circ} \mathrm{C}$, sendo a taxa de aquecimento de $10^{\circ} \mathrm{C} / \mathrm{min}$, mantida no patamar térmico por sessenta minutos e resfriada em forno, conforme curva apresentada na Figura 3. A atmosfera de sinterização era composta $25 \%$ Hidrogênio e $75 \%$ Nitrogênio e se manteve até o resfriamento pleno, temperatura ambiente dos corpos de prova.

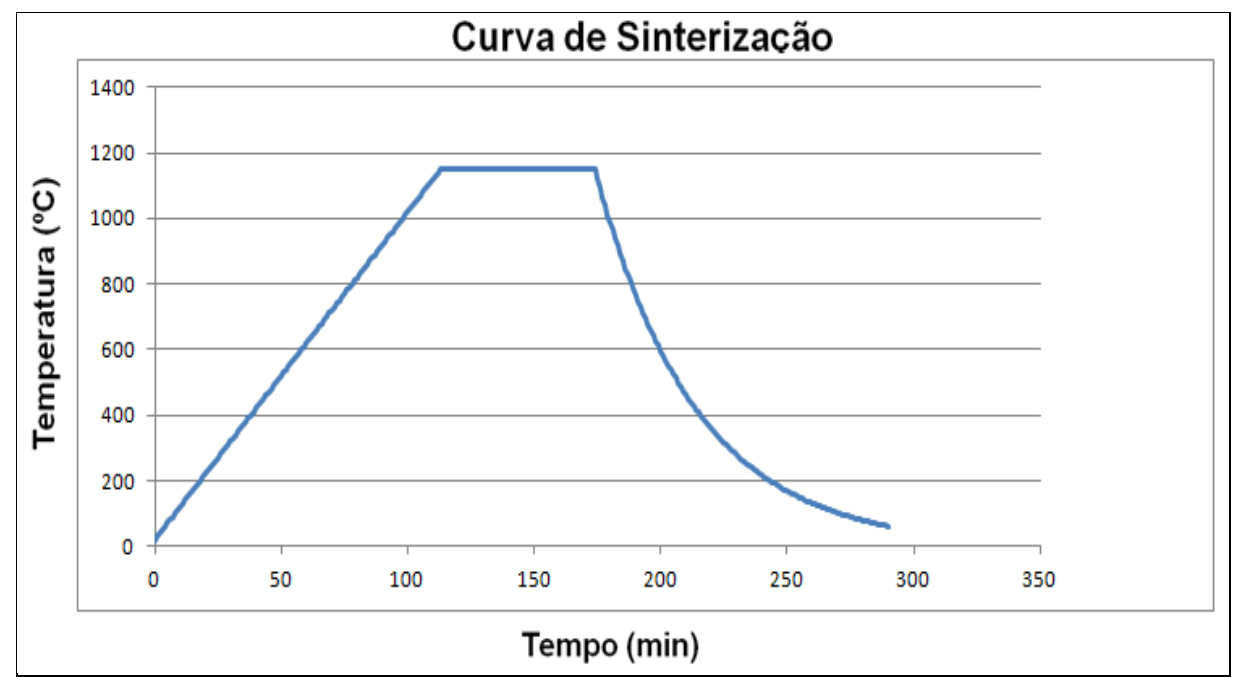

Figura 3. Curva de sinterização utilizada para o SAE 4140.

\footnotetext{
* Contribuição técnica ao $69^{\circ}$ Congresso Anual da ABM - Internacional e ao 14ํㅡㄹ ENEMET - Encontro Nacional de Estudantes de Engenharia Metalúrgica, de Materiais e de Minas, 21 a 25 de julho de 2014, São Paulo, SP, Brasil.
} 


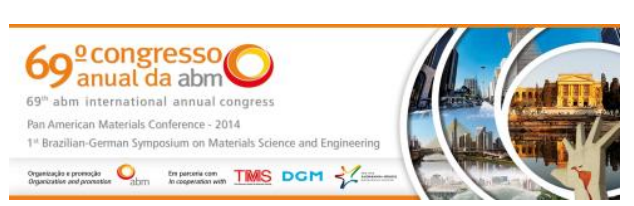

A microestrutura e morfologia microestrutural dos corpos de prova sinterizados foram revelados a partir de amostras previamente polidas e com a utilização de ataque químico de nital para revelar o contorno de grão e analisadas utilizando-se microscopia óptica.

Para avaliação do processo de sinterforjamento foi compactado cinco corpos com pressão de $700 \mathrm{MPa}$ e sinterizados e realizou-se ensaio de compressão, com reduções em altura de 20 e 30\%, a quente e a frio. Considerando para os aços doces e meio doces o tempo para aquecimento homogêneo é de 1 hora por polegada [3], então, os corpos para serem forjados a quente foram aquecidos por 15 minutos antes do ensaio de compressão.

Os corpos de prova com massa de $20 \mathrm{~g}$ aproximadamente e pressão de $700 \mathrm{MPa}$ apresentam condições adequadas para ser utilizada no ensaio de sínter forjamento devido a dimensional ser de fácil manuseio. Os resultados estão apresentados na Tabela 4 e Figura 4.

Foram realizados, também, ensaio de compressão em corpos de prova oriundos do processo de laminação utilizando as mesmas reduções para obtenção da curva tensão $x$ deformação a fim de comparar as variáveis do processo em relação aos corpos de prova.

As faces de todos os corpos de prova foram lixadas para diminuir o atrito interfacial entre estes e as matrizes. Através de uma prensa hidráulica, com a capacidade de 40 tonf, foi executado a compressão dos corpos de prova e, com a utilização de um paquímetro universal foi possível aferir as dimensões dos corpos de prova antes e depois do ensaio.

Para controlar os deslocamentos e os esforços instantâneos foram utilizados um sensor de deslocamento linear e uma célula de carga. Esses dados são manipulados através do programa Catman, a partir do sistema de aquisição de dados HBM, que faz a transferência dos valores obtidos no ensaio.

\section{RESULTADOS E DISCUSSÃO}

A partir das misturas prontas com pós elementares e para se determinar a pressão de compactação adequada foi traçada uma curva de compressibilidade. A Tabela 2 apresenta os dados tendo uma variação de 100 a1000MPa.

Tabela 2. Dados para a curva de compressibilidade AISI 4140

\begin{tabular}{|c|c|c|c|c|c|}
\hline $\begin{array}{c}\text { Pressão } \\
(\mathrm{MPa})\end{array}$ & $\begin{array}{c}\text { Diâmetro } \\
(\mathrm{mm})\end{array}$ & $\begin{array}{c}\text { Altura } \\
(\mathrm{mm})\end{array}$ & $\begin{array}{c}\text { Volume } \\
\left(\mathrm{cm}^{3}\right)\end{array}$ & $\begin{array}{c}\text { Massa } \\
(\mathrm{g})\end{array}$ & $\begin{array}{c}\text { Densidade } \\
\left(\mathrm{g} / \mathrm{cm}^{3}\right)\end{array}$ \\
\hline 0 & & & & & 4,5 \\
\hline 100 & 13.01 & 7,50 & 0,997 & 4,993 & 5,01 \\
\hline 200 & 13.04 & 6,73 & 0,899 & 5,004 & 5,57 \\
\hline 300 & 13.03 & 6,33 & 0,844 & 5,007 & 5,93 \\
\hline 400 & 13.01 & 6,03 & 0,802 & 5,009 & 6,25 \\
\hline 500 & 13.02 & 5,97 & 0,795 & 5,026 & 6,32 \\
\hline 600 & 13.01 & 5,85 & 0,775 & 4,999 & 6,45 \\
\hline 700 & 13.01 & 5,72 & 0,760 & 5,005 & 6,58 \\
\hline 800 & 13.03 & 5,76 & 0,768 & 5,000 & 6,51 \\
\hline 900 & 13.04 & 5,86 & 0,783 & 4,997 & 6,39 \\
\hline 1000 & 13.02 & 5,48 & 0,730 & 4,686 & 6,42 \\
\hline
\end{tabular}

\footnotetext{
* Contribuição técnica ao $69^{\circ}$ Congresso Anual da ABM - Internacional e ao 14ํㅡㄹ ENEMET - Encontro Nacional de Estudantes de Engenharia Metalúrgica, de Materiais e de Minas, 21 a 25 de julho de 2014, São Paulo, SP, Brasil.
} 
Com os dados obtidos foi traçado a curva compressibilidade como mostra a Figura 4.

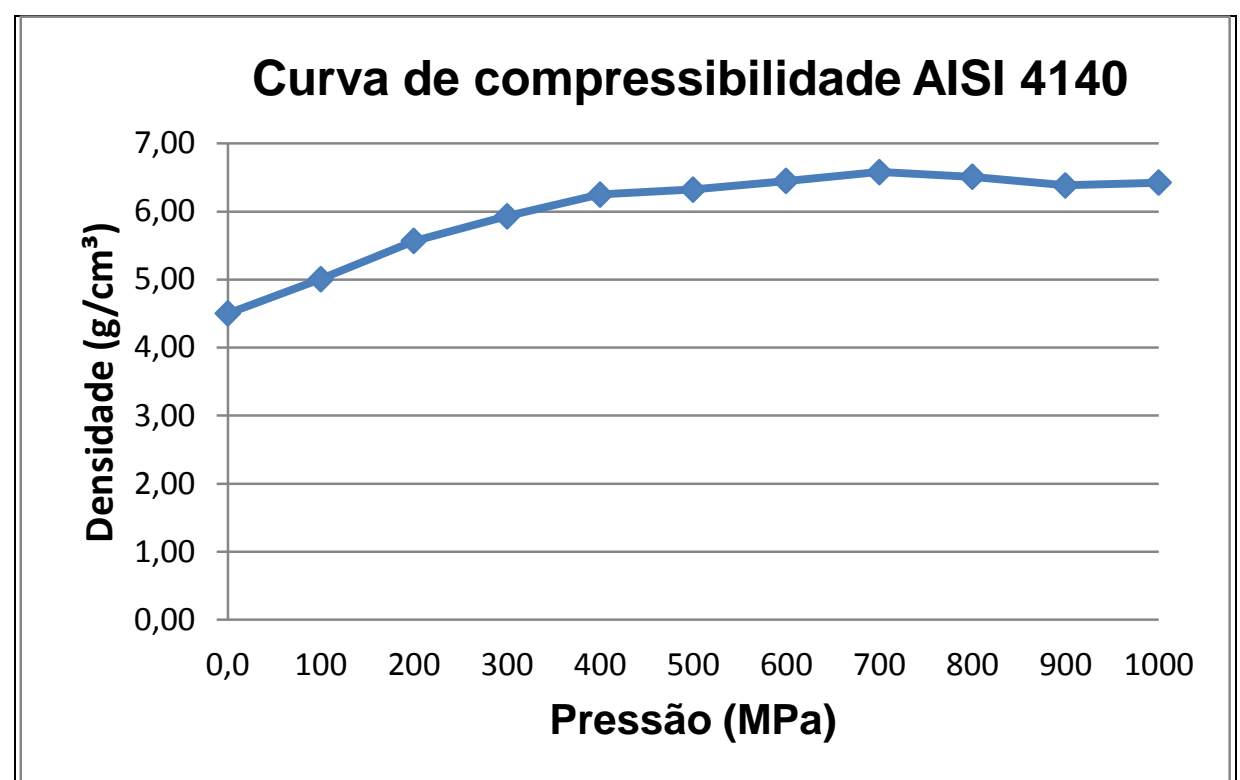

Figura 4. Curva de compressibilidade das amostras SAE 4140

As amostras foram sintetizadas a $1.150^{\circ} \mathrm{C}$ e os resultados estão apresentados na Tabela 3.

Tabela 3. Dados para a curva de compressibilidade SAE 4140 sintetizados.

\begin{tabular}{|c|c|c|c|}
\hline $\begin{array}{c}\text { Pressão } \\
(\mathrm{MPa})\end{array}$ & $\begin{array}{c}\text { Massa } \\
(\mathrm{g})\end{array}$ & $\begin{array}{c}\text { Volume } \\
\left(\mathrm{cm}^{3}\right)\end{array}$ & $\begin{array}{c}\text { Densidade do } \\
\text { sintrizado }\left(\mathrm{g} / \mathrm{cm}^{3}\right)\end{array}$ \\
\hline 100 & 4,92 & 0,77 & 6,39 \\
\hline 200 & 4,98 & 0,76 & 6,55 \\
\hline 300 & 4,97 & 0,75 & 6,63 \\
\hline 400 & 4,95 & 0,73 & 6,78 \\
\hline 500 & 4,97 & 0,74 & 6,72 \\
\hline 600 & 4,95 & 0,72 & 6,88 \\
\hline 700 & 4,97 & 0,72 & 6,90 \\
\hline 800 & 4,96 & 0,73 & 6,79 \\
\hline 900 & 4,95 & 0,72 & 6,88 \\
\hline 1000 & 4,65 & 0,68 & 6,84 \\
\hline
\end{tabular}

A partir dos Dados para a curva de compressibilidade SAE 4140 sintetizados, Tabela 3, foi possível a obtenção da curva de densificação das amostras sinterizadas, conforme exibe a Figura 5.

\footnotetext{
* Contribuição técnica ao 69ำ Congresso Anual da ABM - Internacional e ao 14ํㅡㄹ ENEMET - Encontro Nacional de Estudantes de Engenharia Metalúrgica, de Materiais e de Minas, 21 a 25 de julho de 2014, São Paulo, SP, Brasil.
} 

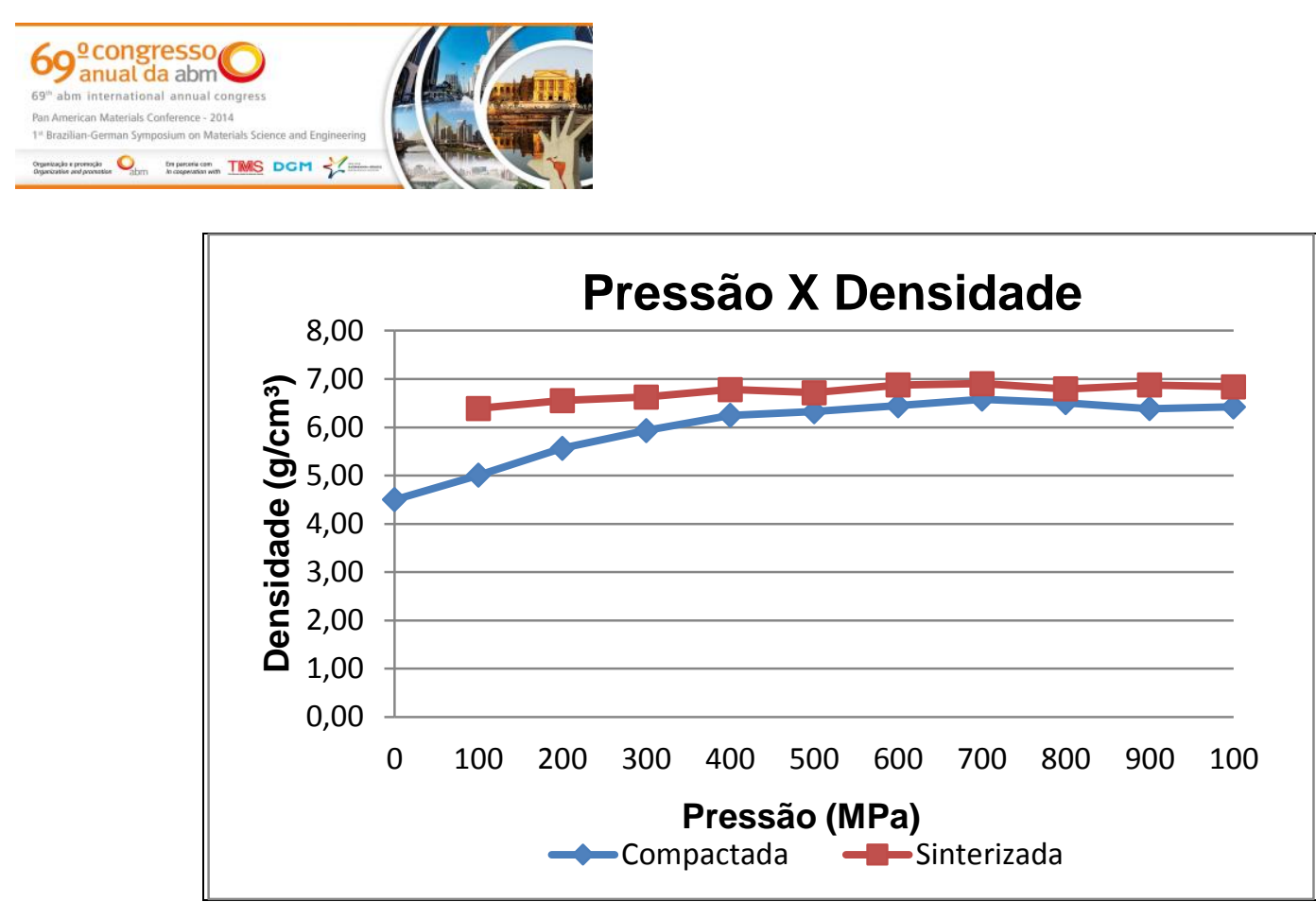

Figura 5. Curva de densificação das amostras sinterizadas do SAE 4140.

Para avaliar as características mecânicas das amostras sinterizadas foram analisadas as propriedades de dureza e microdureza, dividindo as amostras em dois grupos. As peças compactadas com $100 \mathrm{MPa}, 500 \mathrm{MPa}$ e $1000 \mathrm{Mpa}$ analisou-se a microdureza vickers (HV), enquanto, as amostras a $200 \mathrm{MPa}, 600 \mathrm{MPa}$ e $900 \mathrm{MPa}$ utilizou-se a análise da dureza em Rockwell B (HRb).

Os dados das microdurezas estão representados na Figura 6 onde há tendência de crescimento após a pressão de $500 \mathrm{MPa}$ e redução na pressão de $1000 \mathrm{MPa}$ foram realizadas cinco medidas cada amostra. Observa-se que os valores de microdureza são muito baixos e não há significativa diferença entre os mesmos.

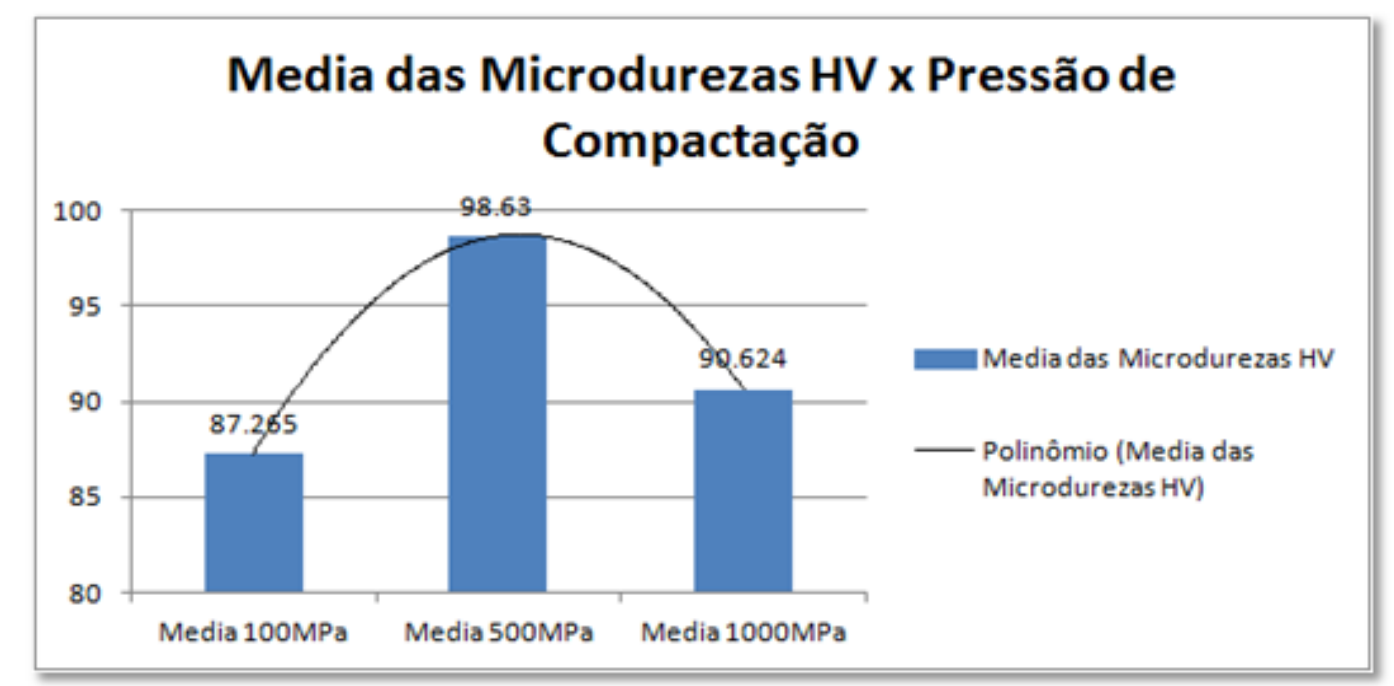

Figura 6. Análise das microdurezas das amostras sinterizadas do SAE 4140.

$\mathrm{Na}$ Figura 7 pode-se verificar a clara tendência de crescimento entre as amostras analisadas e determinar que o ponto ótimo para as propriedades mecânicas é entre 0 intervalo de 600 e $900 \mathrm{MPa}$.

\footnotetext{
* Contribuição técnica ao $69^{\circ}$ Congresso Anual da ABM - Internacional e ao 14ํㅡㄹ ENEMET - Encontro Nacional de Estudantes de Engenharia Metalúrgica, de Materiais e de Minas, 21 a 25 de julho de 2014, São Paulo, SP, Brasil.
} 

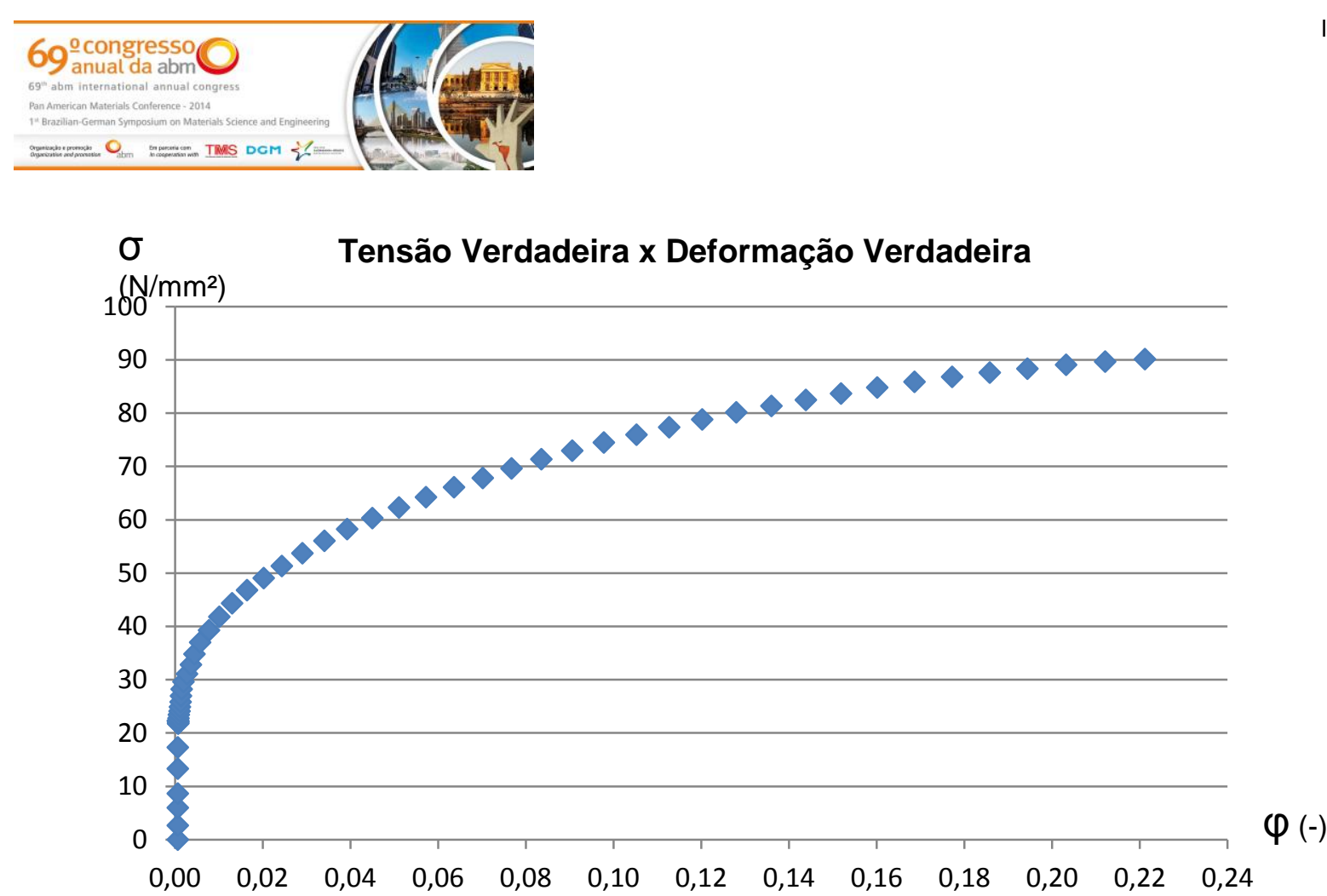

Figure 10. Tensão verdadeira $x$ deformação verdadeira para o ensaio de compressão a quente para o material compactado/sinterizado.

Analisam as curvas verdadeira do ensaio de compressão, nota-se que, precisa maior tensão para promover a deformação no material laminado do que no sinterizado. E ainda o laminado consegue maior deformação verdadeira antes do rompimento. Esta resistência é pelo fato do mesmo possuir grãos alinhados durante o processo anterior ao ensaio. Outro fato importante é que o material sinterizado e conformado a quente aumentou densidade, mas precisou apenas de um quinto da tensão de compressão do material conformado a frio e rompeu com a mesma deformação apresentando necessidade de maior estudo. A Tabela 6 demostra a comparação dos resultados de tensão obtidos nos ensaios de compressão nas três condições da realização do ensaio.

Tabela 6. Valores de tensões em função da deformação verdadeira

\begin{tabular}{|c|c|c|c|}
\hline & $\begin{array}{l}\text { Ensaio a frio do } \\
\text { corpo laminado }\end{array}$ & $\begin{array}{l}\text { Ensaio a frio do corpo } \\
\text { compactado/sinterizado }\end{array}$ & $\begin{array}{l}\text { Ensaio a quente do corpo } \\
\text { compactado/sinterizado }\end{array}$ \\
\hline Tensão & $720 \mathrm{~N} / \mathrm{mm}^{2}$ & $500 \mathrm{~N} / \mathrm{mm}^{2}$ & $90 \mathrm{~N} / \mathrm{mm}^{2}$ \\
\hline Deformação & 0,44 & 0,20 & 0,22 \\
\hline
\end{tabular}

Para todas as amostras sinterizadas e, posteriormente, forjadas, ocorreu uma densificação. O processo de forjamento dos sinterizados promove inicialmente 0 fechamento dos poros, após este processo começa a conformação propriamente dita, onde inicia o escorregamento dos planos. Quando analisadas as metalografias podese notar a redução dos poros, seja por fechamento ou achatamento, apresentado na Figura 11, sendo a Figura 11a a amostra 4 sinterizada e a Figura 11b sendo a amostra 5 sinterizada com $20 \%$ de redução durante a conformação. Observa-se que a amostra sinterizada possui poros maiores que a amostra sinerforjada.

\footnotetext{
* Contribuição técnica ao $69^{\circ}$ Congresso Anual da ABM - Internacional e ao 14ํㅡㄹ ENEMET - Encontro Nacional de Estudantes de Engenharia Metalúrgica, de Materiais e de Minas, 21 a 25 de julho de 2014, São Paulo, SP, Brasil.
} 

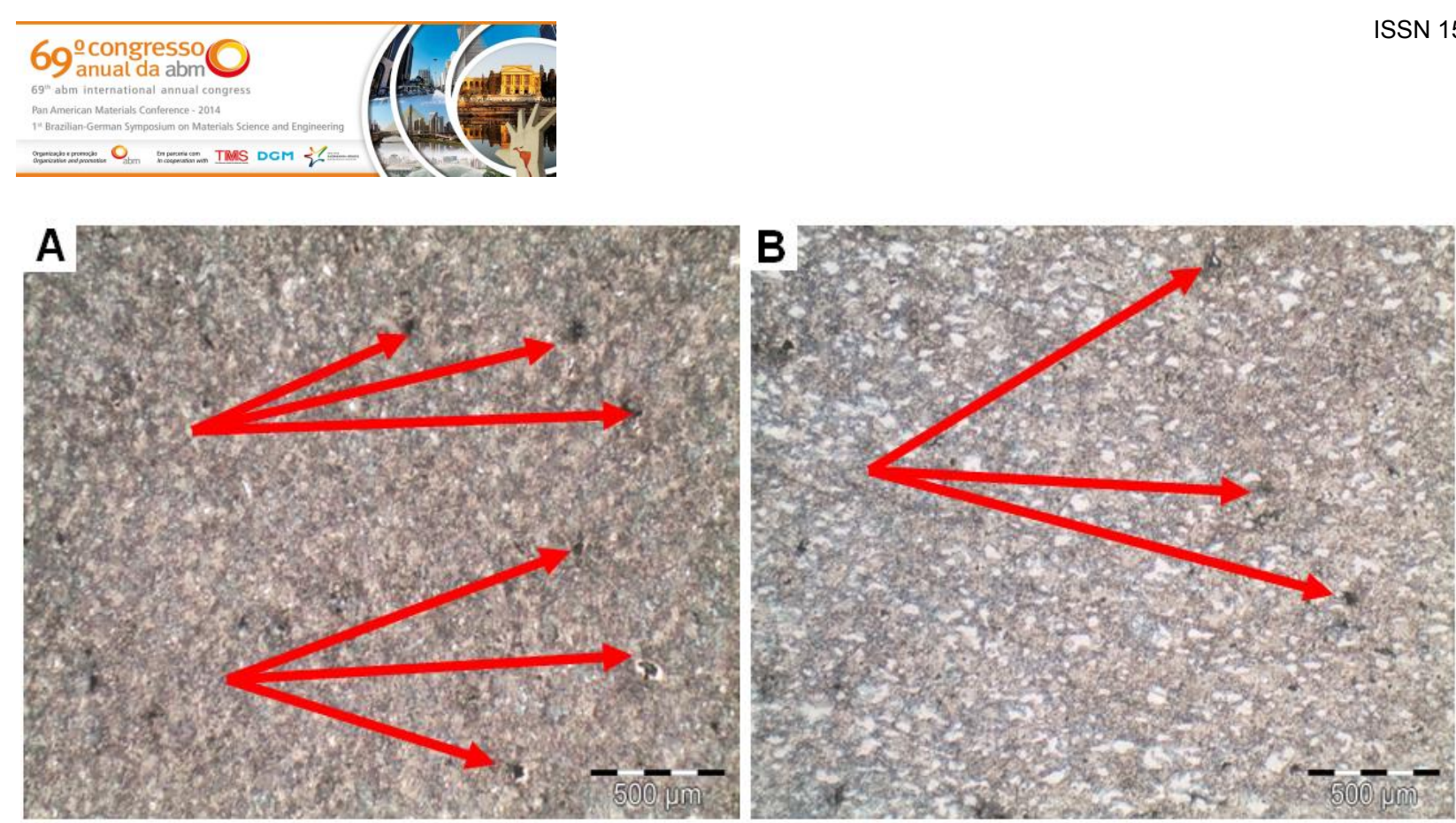

Figure 11. Análise da redução da porosidade das amostras sinterizadas (a) e sinterforjadas (b).

A Figura 12 apresenta amostras sinterforjadas. Sendo a Figura 12a exibe a metalografia da amostra 6 forjada a frio após a sinterização com redução de $30 \%$ e a Figura $12 \mathrm{~b}$ apresenta a amostra 7 forjada a quente com redução e $20 \%$.
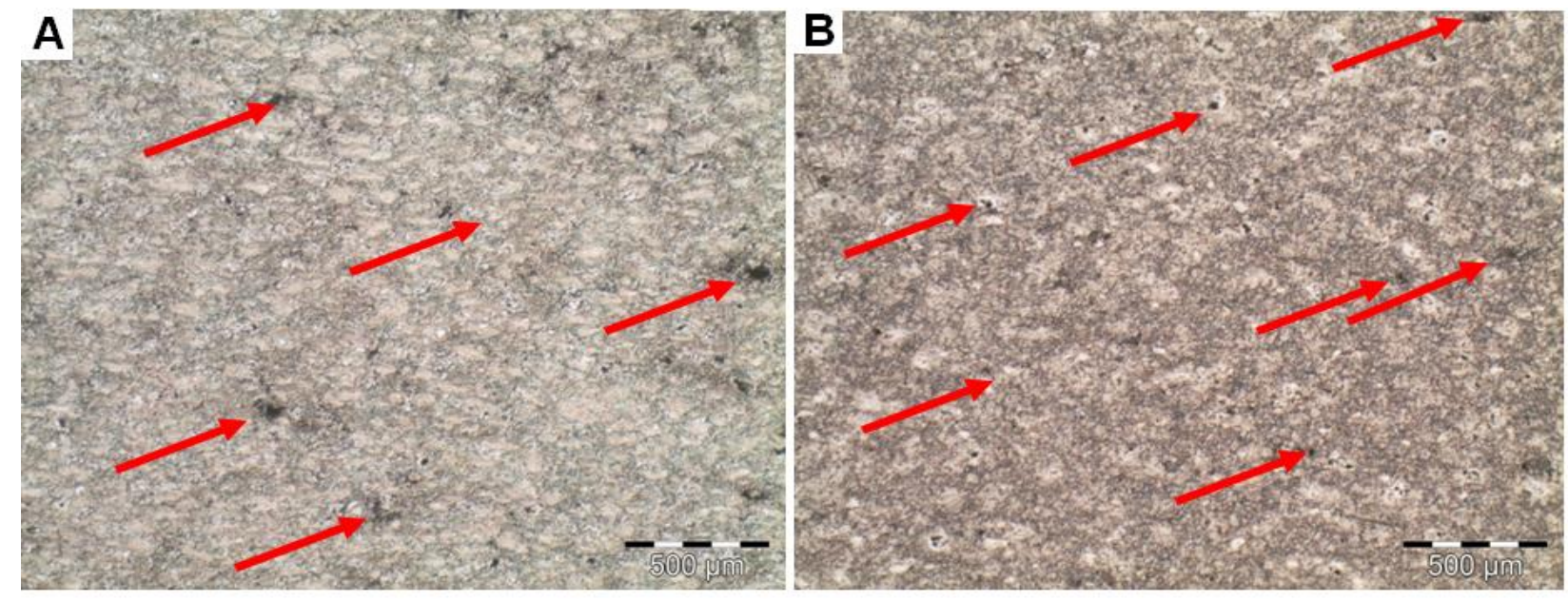

Figura 12. (a) Sinterforjamento a frio da amostra 6 e (b) sinterforjada a quente da amostra 7.

Observa-se que nas Figuras 12a e 12b houve a redução da porosidade das amostras sinterizadas. A amostra sinterforjada possui poros maiores do que a amostra sinterforjada aquente com $20 \%$ de redução. Os poros da redução a quente são muito menores e em menor quantidade do que a conformação a frio. Evidenciando que o processo a quente é o mais indicado. Realizando uma discussão dos dados desde a Tabela 5 e 6 juntamente com as Figuras 8 a 12. Nota-se, que as amostras laminadas possuíam maiores densidades e diminuíram durante a conformação a quente devido a oxidação das mesmas. A densidade das peças sinterizados aumentou com a conformação, que era esperada e sofreu a mesma influencia da oxidação.

A microdureza aumentou significativamente com a conformação das amostras indiferentes do processo de fabricação das peças antes do forjamento indicando que a temperatura associada a uma maior taxa de redução provoca resultados de elevação da microdureza. O melhor resultado encontrado é a amostra sinterizada e forjada com redução de $30 \%$ em altura. As amostras laminada a frio apresentaram uma tensão próxima de $700 \mathrm{~N} / \mathrm{mm}^{2}$ contra o valor próximo de $450 \mathrm{~N} / \mathrm{mm}^{2}$ da amostra

* Contribuição técnica ao 69 Congresso Anual da ABM - Internacional e ao 14ํㅡㄹ ENEMET - Encontro Nacional de Estudantes de Engenharia Metalúrgica, de Materiais e de Minas, 21 a 25 de julho de 2014, São Paulo, SP, Brasil. 


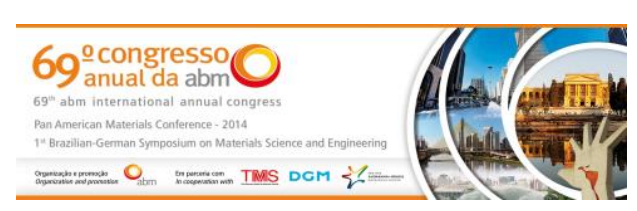

sinterizada. A Figura 13a exibe a amostra 1 laminada sem conformação que mostra a estrutural inicial da barra utilizada na conformação. A Figura 13b mostra a amostra 2 laminada com redução de $20 \%$ de altura por conformação a $1000^{\circ} \mathrm{C}$.

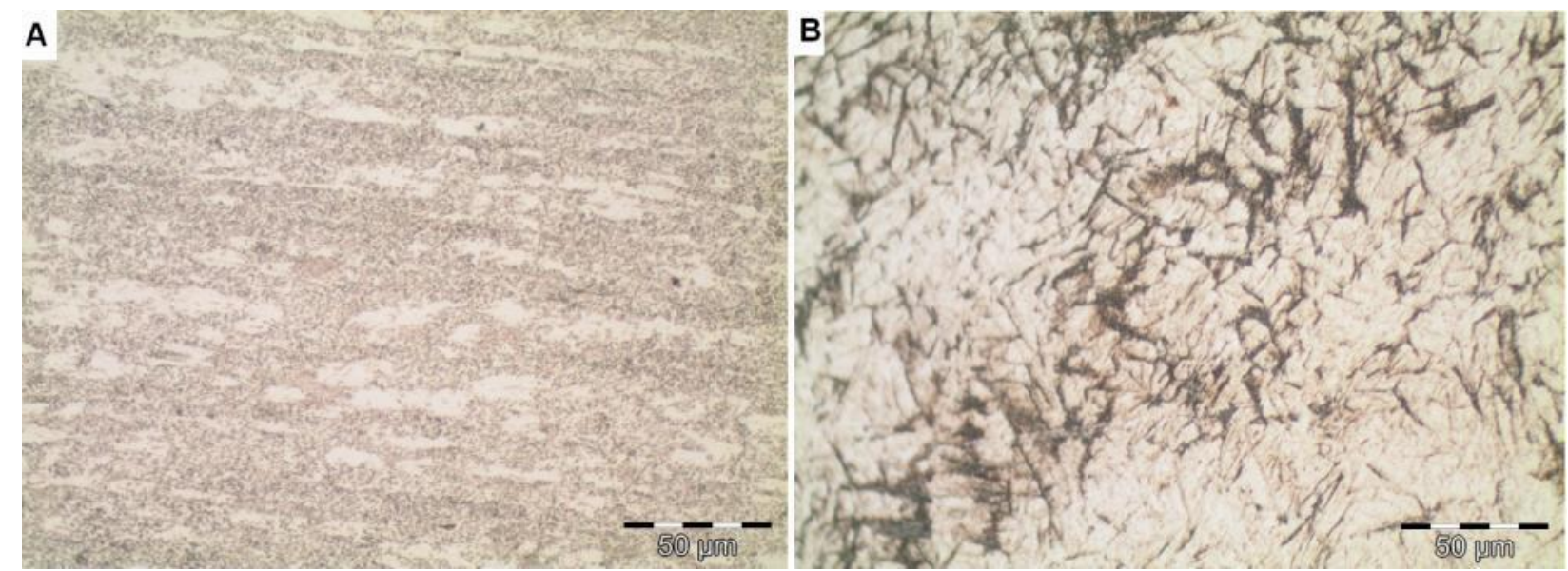

Figura 13. Amostras laminada (a) e forjada com $20 \%$ de redução a $1000^{\circ} \mathrm{C}$ (b).

Observa-se na Figura 13a o sentido de conformação do processo de laminação com tamanho de grão menor que $50 \mu \mathrm{m}$ e alongados. A Figura 13b mostra uma reorganização da microestrutura proveniente do processo de forjamento com tamanho de grão entre 10 e $20 \mu \mathrm{m}$. A Figura 14a exibe a amostra 3 laminada com conformação de $30 \%$ na redução da altura. A Figura $14 \mathrm{~b}$ apresenta a amostra 4 que foi sinterizada e não sofreu o processo de conformação.

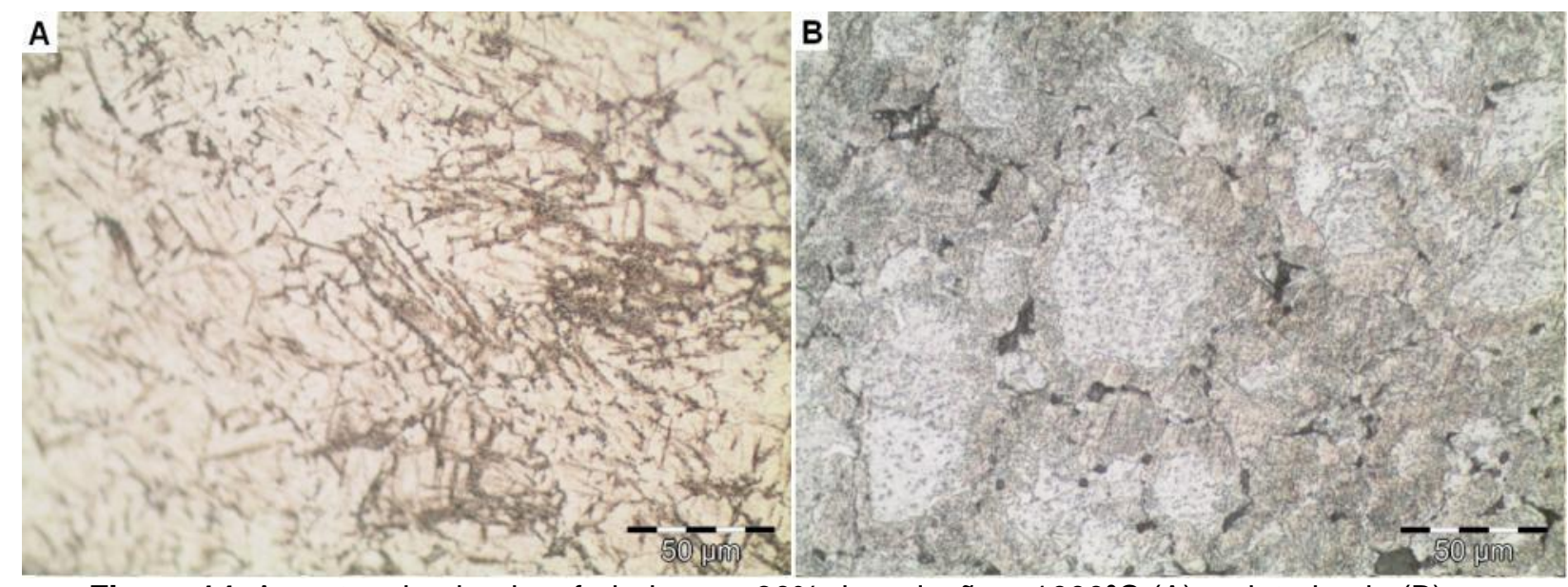

Figura 14. Amostras laminada e forjada com $30 \%$ de redução a $1000^{\circ} \mathrm{C}(\mathrm{A})$ e sinterizada (B)

A Figura 14a mostra que houve pouca diferença microestrutural em comparação com a amostra com $20 \%$ de redução e o tamanho do grão ficou entre 10 e $20 \mu \mathrm{m}$. a Figura $14 \mathrm{~b}$ exibe a microestrutura típica de uma amostra sinterizada com poros e tamanho de grão entre 50 e $100 \mu \mathrm{m}$. A Figura 15a exibe a amostra 5 sinterizada com conformação de $20 \%$ em redução da altura realizado em temperatura ambiente. A Figura 15b mostra a amostra 6 sinterizada com redução de $30 \%$ de altura por conformação em temperatura ambiente.

\footnotetext{
* Contribuição técnica ao 69ำ Congresso Anual da ABM - Internacional e ao 14ํㅡㄹ ENEMET - Encontro Nacional de Estudantes de Engenharia Metalúrgica, de Materiais e de Minas, 21 a 25 de julho de 2014, São Paulo, SP, Brasil.
} 

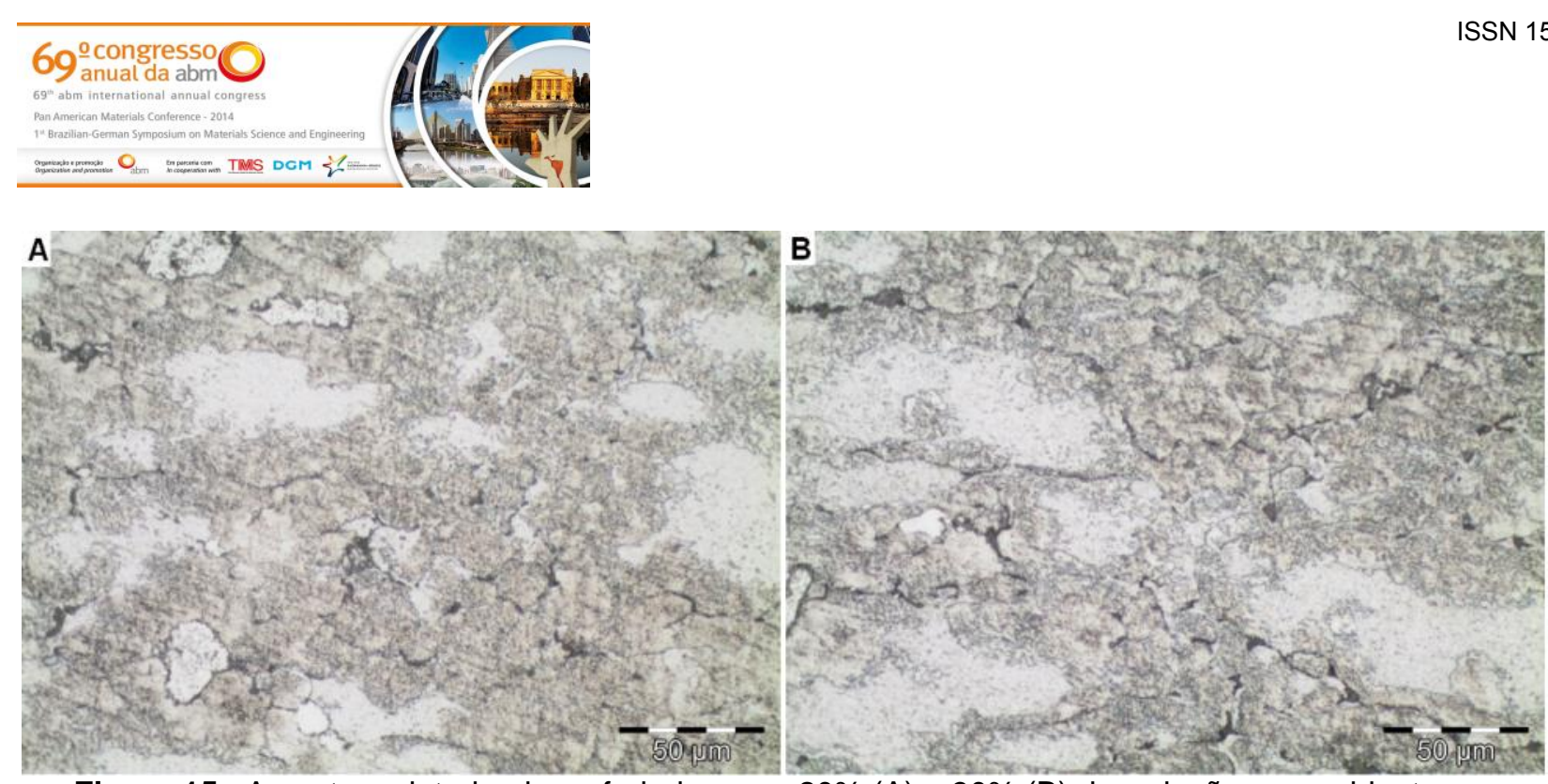

Figura 15. Amostras sinterizadas e forjadas com $20 \%(A)$ e $30 \%(B)$ de redução em ambiente

Nota-se na Figura 15a que houve redução do tamanho de grão, que ficou entre 20 e $80 \mu \mathrm{m}$. A Figura 15b demostra o mesmo tamanho de grão que amostra com redução de $20 \%$. Porém, não há evidências de poros signifiando que a conformação realizou o fechamento dos poros e a diminuição do tamanho de graão aumentano o encruamento e a dureza. A Figura 16a exibe a amostra 7 sinterizada com conformação de $20 \%$ em redução da altura realizado à $1.000^{\circ} \mathrm{C}$. A Figura $16 \mathrm{~b}$ apresenta a amostra 8 sinterizada com redução de $30 \%$ de altura por conformação à $1.000^{\circ} \mathrm{C}$.

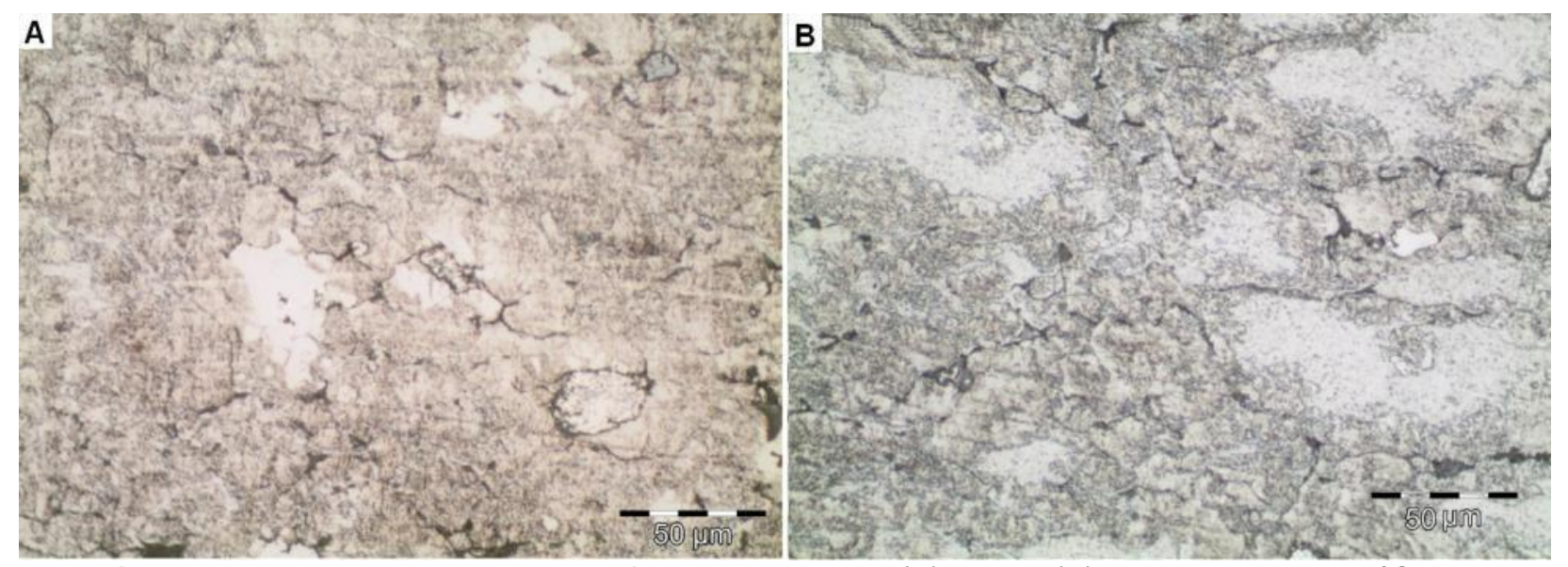

Figura 16. Amostras sinterizadas e forjadas com $20 \%$ (A) e $30 \%$ (B) de redução a $1000^{\circ} \mathrm{C}$

Observa-se na Figura 16a e 16b que não houve redução do tamanho de grão em relação aos mesmos percentuais de conformação em temperatura ambiente.

\section{CONCLUSÃO}

A partida da curva de compressibilidade definiu-se a pressão de compactação de $700 \mathrm{MPa}$ obtem uma otima densificação. Os valores de dureza e microdureza das amostras sinterizadas ficaram menor que $100 \mathrm{HV}$. No ensaio realizado com os corpos de prova obtidos através da compactação de pós elementares houve redução considerál na tensão utilizada para a compressão, assim, para o ensaio à frio a redução é de $200 \mathrm{~N} / \mathrm{mm}^{2}$. Nos ensaios realizados a quente a redução na tensão atinge $410 \mathrm{~N} / \mathrm{mm}^{2}$ comparado realizado a frio nas amostras obtidas a partir da compactação de pós elementares. Durante a conformação a microdurez das amostras sinterizada aumentaram em cerca de $220 \mathrm{HV}$ e comparando-se a dureza das amostras laminadas

\footnotetext{
* Contribuição técnica ao 69ำ Congresso Anual da ABM - Internacional e ao 14ํㅡㄹ ENEMET - Encontro Nacional de Estudantes de Engenharia Metalúrgica, de Materiais e de Minas, 21 a 25 de julho de 2014, São Paulo, SP, Brasil.
} 


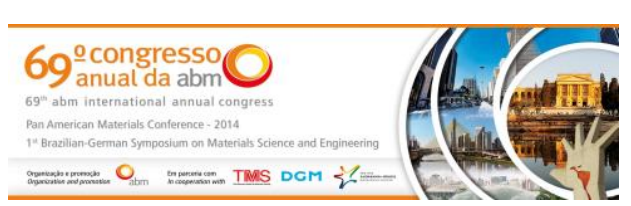

e forjadas. Os valores de microdureza da amostras laminadas e forjadas com $30 \%$ de reduçâo à $1000^{\circ} \mathrm{C}$ e da amostra com a mesma situação de conformação, mas obteida por metalurgia do pó ficaram com 580 e $670 \mathrm{HV}$, respectivamente. Esta dureza elevada das amostra na ultima conformação indica que é devido ao encruamento das amostras, mesmo que, reduzido pelo efeito da temperatura. As metalografia indicam que o forjamento fechou poros e modificou a microestrutura dos materiais sinterizados e reduziu o tamanho de grão de toas as amostras.

\section{Agradecimentos}

Ao Conselho Nacional de Desenvolvimento Científico e Tecnológico (CNPq), ao Laboratório de Transformação Mecânica (LdTM) e à Universidade Federal do Rio Grande do Sul (UFRGS).

\section{REFERÊNCIAS}

1 Chawla N, Williams JJ, Saha R. Mechanical behavior and microstructure characterization of sinter-forged SiC particle reinforced aluminum matrix composites. Journal of Light Metals. 2002;2:215-227.

2 Shanmugasundaram D, Chandramouli R. Tensile and impact behaviour of sinter-forged $\mathrm{Cr}, \mathrm{Ni}$ and Mo alloyed powder metallurgy steels. Materials and Design. 2009;30:344449.

3 Rouessac V, Desgardin G, Gomina M. Influence of the sinter-forging conditions on the mechanical properties of textured bulk (Bi,Pb)-2223 ceramics. Physica C. 1997;282-287: 2573-74.

4 Boutz MMR, Von Minden C, Janssen R, Claussen N. Deformation processing of reaction bonded alumina ceramics; Materials Science and Engineering A. 1997;233: 155-166.

5 Kandavel TK, Chandramouli R, Karthikeyan P. Influence of alloying elements and density on aqueous corrosion behaviour of some sintered low alloy steels. Materials and Design. 2012;40: 336-342.

6 Noudem JG, Guilmeau E, Chateigner D. Recent developments in processing andperformance of hot stacked-sinter forged Bi2223 ceramics. Physica C. 2003;391: 265-271.

7 Noudem JG, Guilmeau E, Chateigner D, Ouladdiaf B, Bourgault D. Performance of hot stacked-sinterforged Bi2223 ceramics. Physica C. 2004;408-410:862-863.

\footnotetext{
* Contribuição técnica ao $69^{\circ}$ Congresso Anual da ABM - Internacional e ao 14ํㅡㄹ ENEMET - Encontro Nacional de Estudantes de Engenharia Metalúrgica, de Materiais e de Minas, 21 a 25 de julho de 2014, São Paulo, SP, Brasil.
} 